\title{
Editorial
}

\section{Animal Organic Farming Meets Pathology}

\author{
Jacques Cabaret ${ }^{*} \S$
}

INRA, IASP 213, 37380 Nouzilly, France

${ }^{\S}$ Guest Editor

Organic farming has developed unevenly throughout the world and under different regulations. Consummers regarded differently the different productions. Herbivore production was considered as a safe one due to its use of usual food (grass grazed on pastures) for these animals, until the "mad cow" public health problem arised. The situation for pig and poultry was considered as inadequate for some consumers, often on ethical grounds. Under organic farming management, prevention is highly important and pathologies are an alert that health management should be revised. The

*Address correspondence to this author at the INRA, IASP 213, 37380 Nouzilly, France; Tel: +33 2 47427768; Fax: +33 247427774

E-mail: jcabaret@tours.inra.fr management of diseases is particularly complicated due to the use of several categories of medecines (phytotherapy and homeopathy and also synthetic allopathic products when needed). The organic farmers need guidance from specialists of animal health and production considering the jungle of available drugs and procedures. The farmers have also their own requirements for constructing an autonomous management of health, and the first paper concentrates on the role of vets in organic animal production. A second paper deals with the construction of farmers' knowledge and who are the advisors in cattle milk production. A third paper intends to understand how farmer may use his knowledge to detect animals in need of a treatment. The last paper concerns poultry and is concentrated on some mechanistic repercussions of organic management on production.

(C) Jacques Cabaret; Licensee Bentham Open.

This is an open access article licensed under the terms of the Creative Commons Attribution Non-Commercial License (http://creativecommons.org/licenses/by-nc/3.0/) which permits unrestricted, non-commercial use, distribution and reproduction in any medium, provided the work is properly cited. 